\title{
Levothyroxine but Not Selenium Increases Endothelial Progenitor Cell Counts in Patients with Hypothyroidism
}

\author{
Roberto Negro ${ }^{a}$ Giacomo Greco ${ }^{b}$ \\ ${ }^{a}$ Division of Endocrinology, 'V. Fazzi' Hospital, Lecce, and ${ }^{\text {b}}$ Faculty of Medicine, San Raffaele Hospital, Milan, Italy
}

\section{Key Words}

Hypothyroidism · Endothelial progenitor cells · Selenium ·

Levothyroxine

\begin{abstract}
Background: Hypothyroidism is a common endocrine disease associated with increased oxidative stress, increased cardiovascular (CV) risk, CV events and endothelial dysfunction. Endothelial progenitor cells (EPCs) are a well-known marker of CV risk. Objective: The aim of this work was to ascertain whether hypothyroidism is associated with lower EPC counts and if treatment with levothyroxine (LT4) or selenium (Se) improves EPC counts compared to placebo. Methods: Hypothyroid patients $(n=100)$ were randomly divided into five groups to receive placebo (group A), LT4 (group B) or Se at doses of $83 \mu \mathrm{g}$ (group C), $166 \mu \mathrm{g}$ (group D) or $249 \mu \mathrm{g}$ (group E) for 3 months. Each group comprised 20 patients: 10 with 'mild' hypothyroidism and 10 with 'severe' hypothyroidism. A healthy control group (group F) with 20 euthyroid subjects was also recruited. Subjects had to be free of CV disease, diabetes and drugs that interfere with EPCs. Anthropometric measurements (height, weight, BMI), blood pressure, fasting lipids and EPC analyses were performed at baseline and after 3 months. Results: EPC counts
\end{abstract}

were significantly lower in hypothyroid patients compared to controls. EPCs increased after 3 months of treatment with LT4, but not with Se at any dosage. CD133+ and CD34+ EPC counts were negatively correlated with thyroid-stimulating hormone $\left(\mathrm{TSH} ; r^{2}=0.523, \mathrm{p}<0.01\right.$ and $r^{2}=0.517, \mathrm{p}<0.01$, respectively) and positively correlated with FT4 $\left(r^{2}=0.394\right.$, $\mathrm{p}<0.01$ and $r^{2}=0.369, \mathrm{p}<0.01$, respectively). TSH and FT4 were the only predictors of EPC counts. Conclusions: Hypothyroidism is associated with low EPC counts. Treatment with LT4, but not Se, can improve EPC counts.

(c) 2016 European Thyroid Association Published by S. Karger AG, Basel

\section{Introduction}

Hypothyroidism is a common endocrine disorder that is associated with increased cardiovascular (CV) risk, in particular with increased risk of congestive heart failure (HF) and coronary heart disease events and mortality [14]. Moreover, elevated lipid levels that are proportional to the thyroid hormone deficiency are a common feature in

Clinical trial number: ISRCTN93811021.

\section{KARGER}

E-Mail karger@karger.com www.karger.com/etj
(C) 2016 European Thyroid Association

Published by S. Karger AG, Basel

2235-0640/16/0052-0100\$39.50/0
Roberto Negro, MD

Division of Endocrinology, 'V. Fazzi' Hospital

Piazza Muratore 1

IT-73100 Lecce (Italy)

E-Mail robnegro@tiscali.it 
hypothyroid patients whose cholesterol levels are decreased by replacement treatment [5]. However, there is no strong scientific proof of increased mortality related to either subclinical or overt hypothyroidism [6]. Lower numbers of circulating endothelial progenitor cells (EPCs) have been associated with an increased CV risk, and one study found altered EPC levels in subclinical hypothyroidism. The EPC levels reverted to normal after replacement treatment with levothyroxine (LT4) [7-9].

Patients with Hashimoto thyroiditis present low-grade chronic inflammation with endothelial dysfunction and altered nitric oxide (NO) availability that in turn regulates EPC self-renewal, viability, migration, proliferation and differentiation [10, 11]. Hypothyroidism, as well as CV diseases like chronic HF, are associated with oxidative stress, in which altered levels of NO, asymmetric dimethyl arginine (ADMA) and glutathione peroxidase enzymes (selenoproteins that remove hydrogen peroxide and harmful lipid hydroperoxides) exacerbate endothelial dysfunction [12-14]. Recently, a study demonstrated that oxidative stress is higher in overt hypothyroid patients than in euthyroid or subclinical hypothyroid patients, and the total antioxidant status is lower in overt hypothyroid subjects compared to the other groups [15].

Selenium (Se) has physiological antioxidant activities. Se deficiency results in reduced selenoprotein glutathione peroxidase activity, while selenoprotein glutathione peroxidase detoxifies hydrogen peroxide $\left(\mathrm{H}_{2} \mathrm{O}_{2}\right)$ and lipid peroxidation [16].

The aim of the present study was to determine EPC levels in hypothyroid patients before and after treatment with LT4 or Se. To do so, we divided hypothyroid patients into treatment groups to receive placebo, LT4 or different doses of Se. EPC levels were also measured in a control group of euthyroid patients.

\section{Patients and Methods}

For the purpose of the study, we prospectively recruited 50 patients with 'mild' autoimmune hypothyroidism (MH) and 50 with 'severe' autoimmune hypothyroidism ( $\mathrm{SH})$. $\mathrm{MH}$ was arbitrarily defined as thyroid-stimulating hormone (TSH) 4.6-10 mIU/l and $\mathrm{SH}$ was defined as TSH 10.1-20 mIU/l (in the presence of positive thyroid peroxidase antibodies, the cut-off was $>16 \mathrm{mIU} / \mathrm{ml}$ ), regardless of FT4 values. Patients with TSH $>20 \mathrm{mIU} / \mathrm{l}$ were not recruited for ethical reasons. Of the 100 recruited patients, 20 subjects were randomly assigned to placebo (group A), 20 to LT4 (starting dose: $1.0 \mu \mathrm{g} / \mathrm{kg} /$ day if TSH $4.6-10.0 \mathrm{mIU} / \mathrm{l}$ and $1.5 \mu \mathrm{g} / \mathrm{kg} /$ day if TSH >10.1 mIU/l; group B), 20 to L-selenomethionine (LSeMet; Syrel ${ }^{\circledR}$ ) $83 \mu \mathrm{g} /$ day (group C), 20 to L-SeMet $166 \mu \mathrm{g} /$ day (group D) and 20 to L-SeMet $249 \mu \mathrm{g} /$ day (group E). In group B, TSH was checked 45 days after treatment initiation and the LT4 dose was adjusted as necessary with the aim of making the patient euthyroid. A control group composed of 20 euthyroid subjects was also recruited (group F). Each hypothyroid group comprised 10 $\mathrm{MH}$ and $10 \mathrm{SH}$ patients. The exclusion criteria were hypertension, $\mathrm{CV}$ disease, diabetes and the use of drugs affecting the EPC concentration. Thyroid ultrasound, anthropometric measurements (e.g. height, weight, BMI), blood pressure, fasting lipids, $\mathrm{HbAlc}$ and EPC levels were analyzed in all patients. Laboratory analyses and anthropometric measures were recorded at baseline and 3 months after enrolment. Adherence to treatment in the SeMet groups was monitored by pill counts. All subjects gave their written informed consent to the study, and the local ethics committee approved the study in April 2015.

\section{Biochemical Measurements}

Serum TSH and FT4 were measured using a third-generation electrochemiluminescence immunoassay (Roche). The reference values were $0.27-4.2 \mathrm{mIU} / \mathrm{l}$ for TSH and 9.3-18.0 $\mathrm{ng} / \mathrm{l}$ (12-33.5 $\mathrm{pmol} / \mathrm{l}$ ) for FT4. Thyroid peroxidase antibody titers were determined using a radioimmunoassay kit (DiaSorin). The reference range was $0-16 \mathrm{IU} / \mathrm{ml}$.

\section{Quantification of Circulating EPCs by Flow Cytometry}

We used a standardized protocol to identify and quantify EPCs, namely the modified International Society for Hematotherapy and Graft Engineering (ISHAGE) sequential gating strategy, as proposed by Schmidt-Lucke et al. [17]. Briefly, $1 \mathrm{ml}$ of whole blood was collected from a forearm vein into EDTA tubes, transported to the cytometry laboratory and processed within 1-2 $\mathrm{h}$ of collection. Hence, $150 \mu \mathrm{l}$ of whole blood was incubated with the following combination of anti-human monoclonal antibodies: $10 \mu \mathrm{l}$ of anti-CD133 conjugated with allophycocyanin (APC; Miltenyi Biotec), $5 \mu \mathrm{l}$ of anti-CD45 conjugated with APC-H7 (Becton Dickinson), $10 \mu \mathrm{l}$ of anti-KDR (also known as type 2 vascular endothelial growth factor receptor, or VEGF-R2) conjugated with phycoerythrin (Sigma) and $10 \mu \mathrm{l}$ of anti-CD34 conjugated with fluorescein isothiocyanate (Becton Dickinson) for $30 \mathrm{~min}$ at $4{ }^{\circ} \mathrm{C}$ in the dark. Red blood cell lysis was performed using FACS Lysing Solution (BD Biosciences) diluted 1:10 (vol/vol) in distilled water and washed with phosphate-buffered saline before flow cytometry acquisition. Data acquisition was performed with a high-performance flow cytometer (FACSCanto II, BD Biosciences). According to the standardized protocol that we used, human circulating EPCs are identified by a minimal antigenic profile that includes at least one marker of stemness/immaturity (CD34 and/or CD133) plus at least one marker of endothelial commitment (KDR). CD45 staining was also performed to exclude cells, such as macrophages, that express 'endothelial-like' proteins [18]. The same operator, who was blinded to the clinical status of the patients, performed all of the cytometric analyses throughout the study.

\section{Statistical Analysis}

Data were analyzed using the SPSS version 15 statistical package (SPSS Inc.). Differences between groups were analyzed using Student's t test or the Mann-Whitney test (when data were not normally distributed). Correlations between EPC counts and other measures were calculated by Spearman's correlation analysis. Linear regression analysis was carried out using EPCs (after log transformation) as the dependent variable after adjusting for age, blood pressure, BMI, lipid levels and the patient group as categor- 


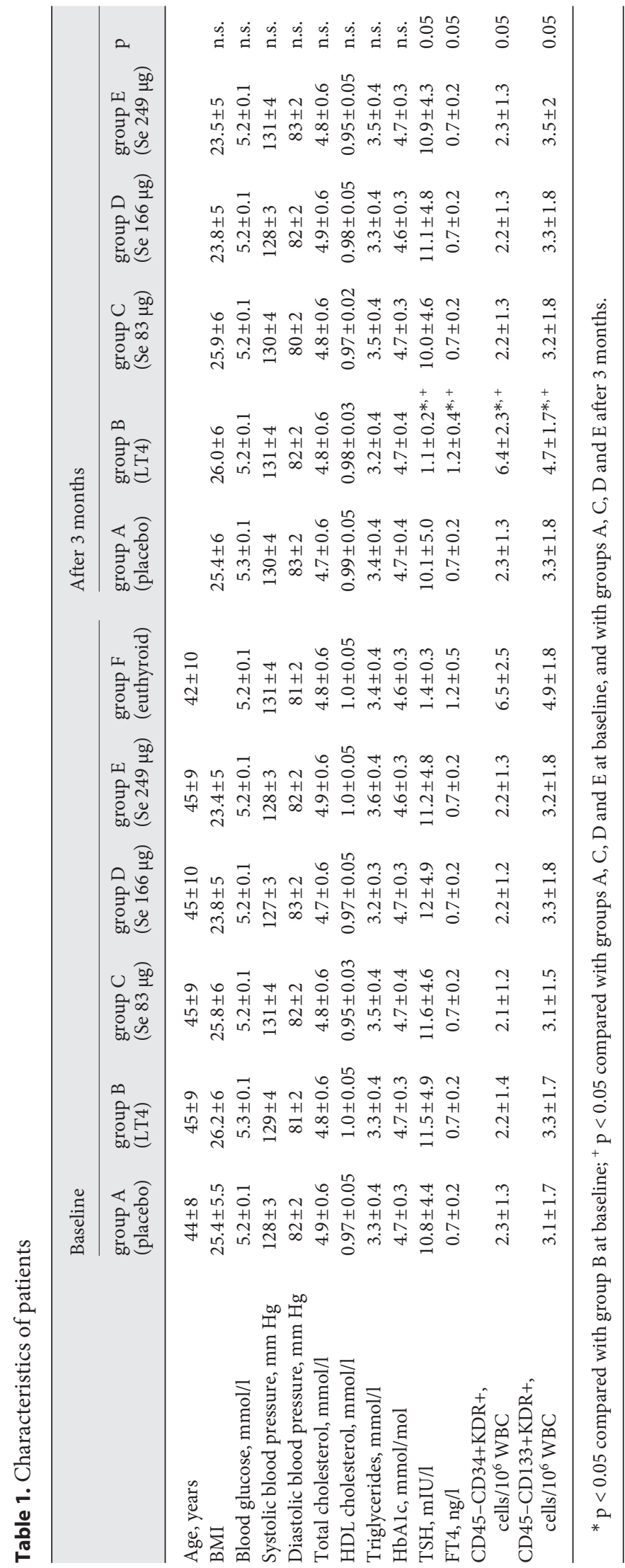

ical variables. Values are provided as the mean \pm standard deviation. Adjustments for multiple comparisons were made using Bonferroni correction. Corrected $p$ values are reported for significant results (two-tailed significance, $\mathrm{p}<0.05$ ).

\section{Results}

The mean pill count adherence in the Se groups was $94.5 \pm 12.9 \%$. At baseline, anthropometric and biochemical measures were similar among the five groups of hypothyroid patients. Groups A-E showed increased TSH levels and decreased FT4 levels compared to the healthy controls (group F; table 1). EPC counts were significantly lower in the five groups of hypothyroid patients compared to the healthy controls. Patients with $\mathrm{MH}$ had higher CD45-CD133+KDR+ and CD45-CD34+KDR+ cell counts compared to $\mathrm{SH}$ patients $\left(4.4\right.$ cells $/ 10^{6} \mathrm{WBC} \pm 1.2$ vs. $2.0 \pm 0.95, \mathrm{p}<0.01$, and 3.2 cells $/ 10^{6} \mathrm{WBC} \pm 1.2$ vs. 1.4 $\pm 0.4, \mathrm{p}<0.01$, respectively). There were significant negative correlations between the levels of TSH and CD45$\mathrm{CD} 133+\mathrm{KDR}+\left(r^{2}=0.523, \mathrm{p}<0.01\right.$; fig. 1a) and CD45$\mathrm{CD} 34+\mathrm{KDR}+\left(r^{2}=0.517, \mathrm{p}<0.01\right)$ cell counts (fig. $\left.1 \mathrm{~b}\right)$. There were also significant positive correlations between levels of FT4 and CD45-CD133+KDR $+\left(r^{2}=0.394, \mathrm{p}<\right.$ 0.01 ; fig. 1c) and CD45-CD34+KDR+ $\left(r^{2}=0.369, \mathrm{p}<\right.$ 0.01 ) cell counts (fig. $1 \mathrm{~d}$ ). In the multiple regression analysis, after adjusting for age, BMI, blood glucose, blood pressure, total cholesterol, HDL cholesterol, triglycerides and HbAlc, both TSH and FT4 levels significantly predicted lower EPC counts: TSH, CD133+, -85 standardized $\beta$-coefficient $(\mathrm{p}<0.001)$, and CD34+, -79 standardized $\beta$-coefficient $(\mathrm{p}<0.001)$; FT4, CD133+, -72 standardized $\beta$-coefficient $(\mathrm{p}<0.001)$, and CD34+, -69 standardized $\beta$-coefficient $(\mathrm{p}<0.001)$. Three months later, compared to baseline, only the LT4-treated group had a significantly increased mean EPC count (other parameters were not significantly affected; table 1 ).

\section{Discussion}

In the present study, we found lower circulating EPC counts in patients with mild or severe hypothyroidism. EPC counts increased significantly with LT4 replacement, but not with Se supplementation. TSH and FT4 values were the only elements associated lower EPC counts after we corrected for other parameters to exclude the possibility that the reduction in EPCs was secondary to other factors. 


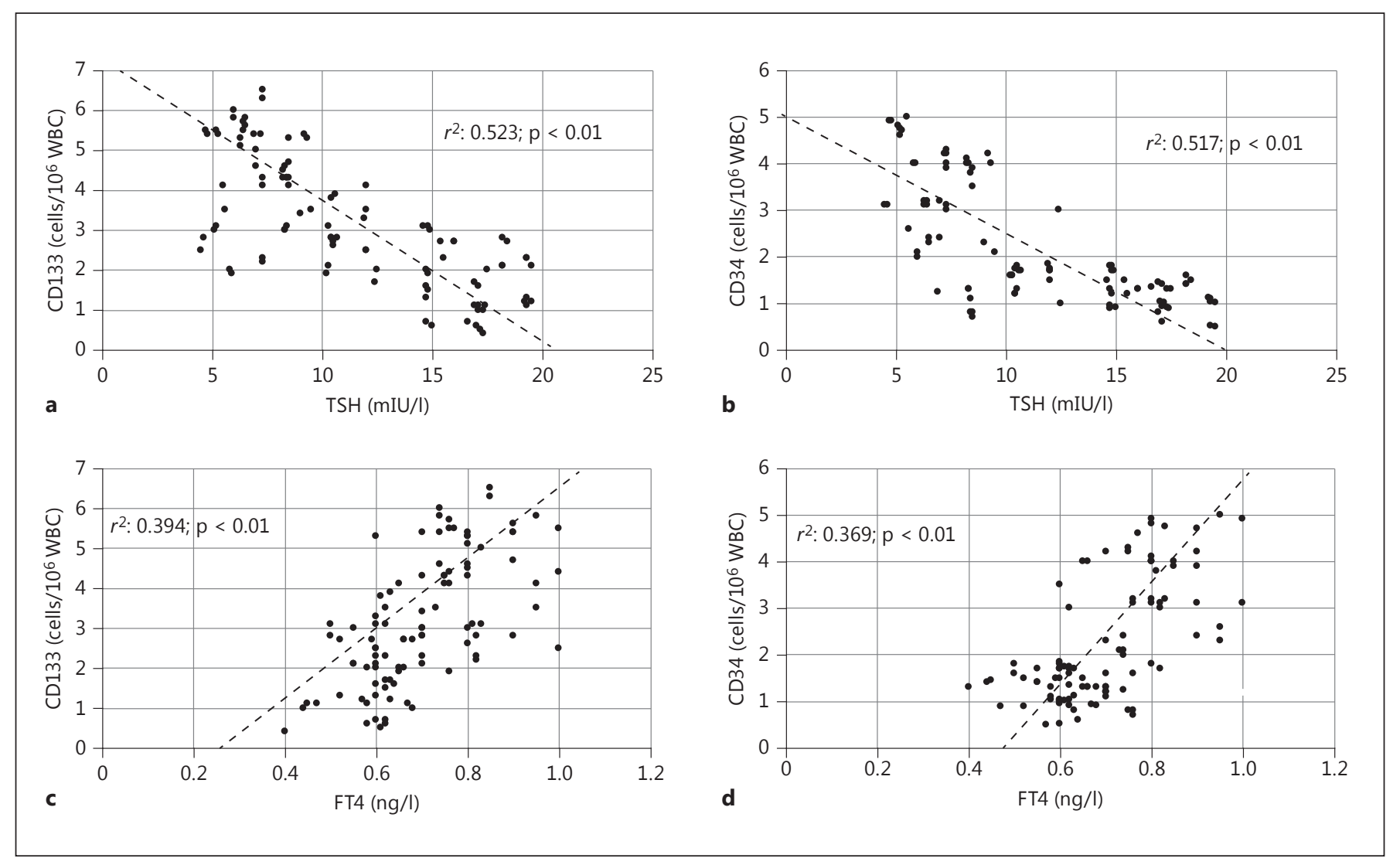

Fig. 1. Associations between TSH and CD133 levels (a), TSH and CD34 levels (b), FT4 and CD133 levels (c), and FT4 and CD34 levels (d).

The presence and extent of endothelial dysfunction predicts the outcome in patients with $\mathrm{CV}$ risk factors and in patients with coronary artery disease (CAD). In patients with CAD, isolated EPCs have an impaired migratory response, and a negative correlation between EPCs and the severity of CAD has been demonstrated [19]. This is likely a result of endothelial dysfunction, which is a characteristic of patients with CAD, in whom EPC counts are strongly associated with CAD risk factors [18]. Moreover, in HF patients, the CD34+ count shows a significant correlation with the severity of disease (the higher the EPC count, the milder the disease) [20]. Our finding that reduced EPCs are associated with hypothyroidism represents an element that is common to hypothyroidism, adverse CV events and CV risk factors. Hypothyroidism is associated with a number of CV risk factors, such as hypercholesterolemia, endothelial dysfunction, diastolic dysfunction and reduced endothelial-mediated coronary reserve flow $[21,22]$. In patients with untreated Hashimoto thyroiditis, the risk of developing coronary heart disease is significantly increased with respect to both healthy controls and to patients with Hashimoto thyroiditis who have been treated with LT4 for at least 1 year [23]. Endothelial dysfunction and carotid intima media thickness are common elements in hypothyroid patients, in whom reduced NO synthesis and increased ADMA levels have been observed $[24,25]$. Indeed, the altered balance between NO synthesis and ADMA negatively influences the EPC count. For example, in patients with stable angina, $\mathrm{ADMA}$ is related to the severity of $\mathrm{CAD}$, inversely correlated with the number of circulating CD34+/ CD133+ progenitor cells, and represses the differentiation of EPCs in a concentration-dependent manner [26]. Patients with subclinical hypothyroidism are predisposed to endothelial dysfunction. In a clinical study, Turemen et al. [27] used the brachial artery response to endothelium-dependent (flow-mediated dilatation, FMD) and endothelium-independent (sublingual nitroglycerin, NTG) stimuli as an indicator of endothelial dysfunction. They found that patients with subclinical hypothyroidism had 
a significantly lower FMD and NTG response compared to controls, and FMD impairment was correlated with serum TSH levels. The findings of Balzan et al. [28] that the TSH receptor is expressed by microvascular endothelial cells suggests a possible mechanism for a direct association between elevated levels of TSH and endothelial dysfunction, and the hypothesis of a direct effect by TSH on endothelial tissue is supported by at least two studies. In the first, Dardano et al. [29] observed that impaired FMD is induced by recombinant human TSH acutely administered to patients being monitored for differentiated thyroid carcinoma. In the second, conducted by Tian et al. [30], it was observed that elevated TSH levels promote endothelial dysfunction in human umbilical vein endothelial cells by attenuating eNOS and prostacyclin (PGI2) expression in a dose- and time-dependent manner.

Patients with chronic autoimmune thyroiditis and hypothyroidism also present a state of low-grade inflammation and oxidative stress. Oxidative stress in particular progressively increases as thyroid dysfunction worsens, and Se deficiency has been associated with increased rates of thyroid disease, especially thyroid autoimmunity and hypothyroidism [31, 32]. Therefore, in the present study, we further explored the hypothesis that the antioxidant activity of Se may have an impact on EPC counts, i.e. that low EPC counts may be due to or associated with increased oxidative stress, independent of thyroid function. Our results indicate that Se does not influence the EPC count, regardless of the administered Se dosage.

Our study has some limitations. For example, serum Se concentrations were not measured at the time of enrolment or at the end of the study period. Thus, we were unable to determine whether our study population was Se deficient, but data from previously published Italian studies allow us to hypothesize that our study population was marginally Se deficient $[33,34]$. Regardless, based on the participants' adherence to Se treatment, we are able to affirm with a high degree of certainty that the lack of an effect by Se was not due to poor patient compliance.

Although the short follow-up time (3 months) may have contributed to the lack of any effect exerted by Se supplementation, our findings demonstrate that hypothyroidism is associated with lower EPC counts. Moreover, LT4 at physiological concentrations, but not Se, can restore EPC counts.

\section{Disclosure Statement}

The authors have nothing to disclose.

\section{References}

1 Canaris GJ, Manowitz NR, Mayor G, Ridgway EC: The Colorado thyroid disease prevalence study. Arch Intern Med 2000;160:526-534.

-2 Hak AE, Pols HA, Visser TJ, Drexhage HA, Hofman A, Witteman JC: Subclinical hypothyroidism is an independent risk factor for atherosclerosis and myocardial infarction in elderly women: the Rotterdam Study. Ann Intern Med 2000;132:270-278.

3 Walsh JP, Bremner AP, Bulsara MK, O’Leary P, Leedman PJ, Feddema P, Michelangeli V: Subclinical thyroid dysfunction as a risk factor for cardiovascular disease. Arch Intern Med 20015;165:2467-2472.

4 Imaizumi M, Akahoshi M, Ichimaru S, Nakashima E, Hida A, Soda M, Usa T, Ashizawa K, Yokoyama N, Maeda R, Nagataki S, Eguchi $\mathrm{K}$ : Risk for ischemic heart disease and allcause mortality in subclinical hypothyroidism. J Clin Endocrinol Metab 2004;89:33653370.

5 Danese MD, Ladenson PW, Meinert CL, Powe NR: Effect of thyroxine therapy on serum lipoproteins in patients with mild thyroid failure: a quantitative review of the literature. J Clin Endocrinol Metab 2000;85:29933001.
6 Thvilum M, Brandt F, Brix TH, Hegedüs L: A review of the evidence for and against increased mortality in hypothyroidism. Nat Rev Endocrinol 2012;8:417-424.

7 Hill JM, Zalos G, Halcox JP, Schenke WH, Waclawiw MA, Quyyumi AA, Finkel T: Circulating endothelial progenitor cells, vascular function, and cardiovascular risk. N Engl J Med 2003;348:593-600.

\$8 Werner N, Kosiol S, Schiegl T, Ahlers P, Walenta K, Link A, Böhm M, Nickenig G: Circulating endothelial progenitor cells and cardiovascular outcomes. N Engl J Med 2005; 353:999-1007.

-9 Shakoor SK, Aldibbiat A, Ingoe LE, Campbell SC, Sibal L, Shaw J, Home PD, Razvi S, Weaver JU: Endothelial progenitor cells in subclinical hypothyroidism: the effect of thyroid hormone replacement therapy. J Clin Endocrinol Metab 2010;95:319-322.

-10 Taddei S, Caraccio N, Virdis A, Dardano A, Versari D, Ghiadoni L, Ferrannini E, Salvetti A, Monzani F: Low-grade systemic inflammation causes endothelial dysfunction in patients with Hashimoto's thyroiditis. J Clin Endocrinol Metab 2006;91:5076-5082.
11 Bonafè F, Guarnieri C, Muscari C: Nitric oxide regulates multiple functions and fate of adult progenitor and stem cells. J Physiol Biochem 2015;71:141-153.

12 de Lorgeril M, Salen P: Selenium and antioxidant defenses as major mediators in the development of chronic heart failure. Heart Fail Rev 2006;11:13-17.

13 Suchitra MM, Suresh V, Reddy VS, Sachan A, Srinivas Rao PV, Bitla AR: Association of lipid peroxidation with endothelial dysfunction in patients with overt hypothyroidism. Exp Clin Endocrinol Diabetes 2013;121: 306-309.

14 Nanda N, Bobby Z, Hamide A, Koner BC, Sridhar MG: Association between oxidative stress and coronary lipid risk factors in hypothyroid women is independent of body mass index. Metabolism 2007;56:1350-1355.

15 Ateș İ, Yilmaz FM, Altay M, Yilmaz N, Berker D, Güler S: The relationship between oxidative stress and autoimmunity in Hashimoto's thyroiditis. Eur J Endocrinol 2015;173:791799.

16 Rayman MP: Selenium and human health Lancet 2012;379:1256-1268. 
-17 Schmidt-Lucke C, Fichtlscherer S, Aicher A, Tschope C, Schultheiss HP, Zeiher AM, Dimmeler S: Quantification of circulating endothelial progenitor cells using the modified ISHAGE protocol. PLoS One 2010;5:e13790.

18 Ingram DA, Caplice NM, Yoder MC: Unresolved questions, changing definitions, and novel paradigms for defining endothelial progenitor cells. Blood 2005;106:1525-1531.

19 Vasa M, Fichtlscherer S, Aicher A, Adler K, Urbich C, Martin H, Zeiher AM, Dimmeler S: Number and migratory activity of circulating endothelial progenitor cells inversely correlate with risk factors for coronary artery disease. Circ Res 2001;89:E1-E7

20 Nonaka-Sarukawa M, Yamamoto K, Aoki H, Nishimura Y, Tomizawa H, Ichida M, Eizawa T, Muroi K, Ikeda U, Shimada K: Circulating endothelial progenitor cells in congestive heart failure. Int J Cardiol 2007;119:344-348.

-21 Razvi S, Ingoe L, Keeka G, Oates C, McMillan C, Weaver JU: The beneficial effect of L-thyroxine on cardiovascular risk factors, endothelial function, and quality of life in subclinical hypothyroidism: randomized, crossover trial. J Clin Endocrinol Metab 2007;92:17151723.

22 Biondi B, Galderisi M, Pagano L, Sidiropulos M, Pulcrano M, D’ Errico A, Ippolito S, Rossi A, de Divitiis O, Lombardi G: Endothelialmediated coronary flow reserve in patients with mild thyroid hormone deficiency. Eur J Endocrinol 2009;161:323-329.
23 Chen WH, Chen YK, Lin CL, Yeh JH, Kao $\mathrm{CH}$ : Hashimoto's thyroiditis, risk of coronary heart disease, and L-thyroxine treatment: a nationwide cohort study. J Clin Endocrinol Metab 2015;100:109-114.

24 Beckman JS, Koppenol WH: Nitric oxide, superoxide, and peroxynitrite: the good, the bad, and the ugly. Am J Physiol 1996;40: C1424-C1437.

25 Ito A, Tsao PS, Adimoolam S, Kimoto M, Ogawa T, Cooke JP: Novel mechanism for endothelial dysfunction: dysregulation of dimethylarginine dimethylaminohydrolase. Circulation 1999;99:3092-3095.

26 Thum T, Tsikas D, Stein S, Schultheiss M, Eigenthaler M, Anker SD, Poole-Wilson PA, Ertl G, Bauersachs J: Suppression of endothelial progenitor cells in human coronary artery disease by the endogenous nitric oxide synthase inhibitor asymmetric dimethylarginine. J Am Coll Cardiol 2005;46:1693-1701.

27 Turemen EE, Cetinarslan B, Sahin T, Canturk Z, Tarkun I: Endothelial dysfunction and low grade chronic inflammation in subclinical hypothyroidism due to autoimmune thyroiditis. Endocr J 2011;58:349-354.

28 Balzan S, Del Carratore R, Nicolini G, Beffy P, Lubrano V, Forini F, Iervasi G: Proangiogenic effect of TSH in human microvascular endothelial cells through its membrane receptor. J Clin Endocrinol Metab 2012;97:1763-1770.

29 Dardano A, Ghiadoni L, Plantinga Y, Caraccio N, Bemi A, Duranti E, Taddei S, Ferrannini E, Salvetti A, Monzani F: Recombinant human thyrotropin reduces endothelium-dependent vasodilation in patients monitored for differentiated thyroid carcinoma. J Clin Endocrinol Metab 2006;91:4175-4178.
30 Tian L, Zhang L, Liu J, Guo T, Gao C, Ni J: Effects of TSH on the function of human umbilical vein endothelial cells. J Mol Endocrinol 2014;52:215-222.

- 31 Metwalley KA, Farghaly HS, Saad K, Othman HA: Oxidative status in children and adolescents with autoimmune thyroiditis. Clin Exp Med 2015, Epub ahead of print.

-32 Wu Q, Rayman MP, Lv H, Schomburg L, Cui B, Gao C, Chen P, Zhuang G, Zhang Z, Peng X, Li H, Zhao Y, He X, Zeng G, Qin F, Hou P, Shi B: Low population selenium status is associated with increased prevalence of thyroid disease. J Clin Endocrinol Metab 2015;100: 4037-4047.

33 Maggio M, Ceda GP, Lauretani F, Bandinelli S, Dall'Aglio E, Guralnik JM, Paolisso G, Semba RD, Nouvenne A, Borghi L, Ceresini G, Ablondi F, Benatti M, Ferrucci L: Association of plasma selenium concentrations with total IGF-1 among older community-dwelling adults: the InCHIANTI study. Clin Nutr 2010;29:674-677.

34 Giacosa A, Faliva MA, Perna S, Minoia C, Ronchi A, Rondanelli M: Selenium fortification of an Italian rice cultivar via foliar fertilization with sodium selenate and its effects on human serum selenium levels and on erythrocyte glutathione peroxidase activity. Nutrients 2014;6:1251-1261. 